\title{
Towards a model of emergency department congestion
}

\author{
Malcolm Brady \\ Dublin City University \\ Dublin 9 \\ Ireland \\ Email: malcolm.brady@dcu.ie \\ Vikas Kumar \\ University of West of England \\ Bristol \\ United Kingdom \\ Email: vikas.kumar@uwe.ac.uk \\ PJ Byrne \\ Dublin City University \\ Dublin 9 \\ Ireland \\ Email:pj.byrne@dcu.ie \\ Gerry Conyngham \\ Dublin City University \\ Dublin 9 \\ Ireland \\ Email: gerry.conyngham@dcu.ie \\ Paul Liston \\ Dublin City University \\ Dublin 9 \\ Ireland \\ Email:paul.liston@dcu.ie \\ Peadar Gilligan \\ Beaumont Hospital \\ Dublin 9 \\ Ireland \\ Email: peadargilligan@beaumont.ie
}

Paper published in International Journal of Healthcare Technology and Management, 2017, 16(3-4), pp. 303-318 


\begin{abstract}
The purpose of this paper is to examine the flow of patients through the emergency department of a large suburban acute general hospital and the factors that influence overcrowding and congestion. The paper broadly draws on the input-process-output systems paradigm as a basis for examining emergency department patient throughput. A data set of all attendances at the emergency department of a large suburban acute general hospital during the course of a full calendar year was examined using statistical tools. The analysis found that the major influencers of length of stay were patient-related factors such as age, severity of ailment (triage category), and whether or not the patient was admitted into the main hospital. Patients admitted into the hospital had significantly longer length of stay in emergency than those who were not admitted. The main influencers of patient arrivals were temporal factors such as time of day and day of arrival. These influencing factors are formed into a tentative model of emergency department congestion.
\end{abstract}

Keywords: emergency department, age, length of stay, throughput, congestion, admission, hospital 
The emergency department is a critical element of most national health care systems. It is the primary entry point to the health system for many people and their main source of acute care (Lim et al., 2002). Arrivals at the emergency department are volatile making them difficult to manage. Restricted budgets lead to shortage of human resources and facilities. These and other factors regularly lead to a mismatch of supply and demand with consequent overcrowding, long waiting times for patients and reduced job satisfaction for staff (Rondeau et al., 2005). Patient length of stay in the emergency department is a critical operational parameter (Khare et al., 2009). Long length of stay can in turn lead to blocking of emergency beds, longer waiting times for treatment for new arrivals and exacerbation of the problem of overcrowding and congestion. As length of stay increases so does the risk of adverse events such as subsequent admission into hospital and short term mortality (Guttman et al., 2011).

The focus of this paper is to examine the flow of patients through the emergency department of a large suburban acute general hospital in Dublin, a major European city. In particular the paper examines the factors influencing congestion and overcrowding. Available to the research team was a data set representing all attendances at the emergency department during the course of a full calendar year. Statistical tools and techniques were used to examine and analyse the data set. The input-process-output systems paradigm from the field of operations management provides a broad framework for the analysis. 
The major influencers of overcrowding and congestion were the number of patients arriving in the emergency department and the length of stay of patients in the department. The research found that the major influencers of length of stay were patient-related factors such as age, severity of ailment (measured as triage category), and whether or not the patient was admitted into the main hospital. Patients admitted into the hospital have significantly longer length of stay in emergency than those who are not admitted. The main influencers of patient arrivals were temporal factors such as time and day of arrival. These influencing factors are formed into a model of emergency department congestion. The remainder of the paper is laid out as follows: first, the

relevant literature is briefly reviewed; second, the data set is introduced and the analytical methodology discussed; third, the findings from the analysis are presented; the fourth section presents a formal influence model of emergency department congestion; the final section concludes.

\section{Literature Review}

Dobrzykowski et al. (2013) highlight the service delivery system as one of the key topic areas in the small but growing literature on healthcare within the operations management field. This review focuses on the literature dealing with patient flow through the emergency department. The literature is examined under the three headings of the systems paradigm: input, process and output. 
With respect to inputs, Richardson (1998) found higher rates of patient admission during weekdays than at weekends and higher rates during working hours than after working hours, reflecting a tendency for patients with minor injuries to attend at convenient times. Xu et al. (2013) found that patients with less severe triage categories are more likely to arrive on weekdays and during warmer weather whereas patients with severe conditions tend to attend immediately and not delay. Wargon et al. (2010) found that more patients arrived on Mondays than on other days of the week and more arrived in June than in other months of the year. Maull et al. (2009) found that more patients arrive during summer months than during winter months. In terms of time of the day, Cerrito and Pecoraro (2005) found that 10.00 a.m. was a bifurcation time after which treatment duration increases dramatically. Richardson (1998) found that admission rates increase with age.

With respect to process, Abo-Hamad and Arisha (2013) found average length of stay of over nine hours in the emergency department of a major urban hospital. Biber et al. (2013) found a correlation between age and length of stay, with elderly trauma patients experiencing statistically longer lengths of stay. Lin et al. (2012) used data mining techniques to examine the triage data of a major hospital and concluded that length of stay and the triage category are key parameters in determining emergency department costs. 
The literature also has examined ways in which to improve the performance of the emergency department. Cochran and Roche (2009) examined the 'split patient flow' approach to reducing the number of 'did-not-waits' or 'walk-aways' (people who choose to leave the emergency room without treatment) which requires streaming of less and more urgent patients. However, a number of issues arise with such 'fast track' approaches: dealing quickly with less urgent cases to free up room in the emergency department may have a negative impact on waiting time for more serious cases. Van der Vaart et al. (2011) discuss a number of approaches to improving the triage process and the prioritization of patients for treatment and discharge.

With respect to output, the literature is sparse on patient exit from the emergency department and in particularly the handover of patients from the emergency department to the hospital proper. Herein lies an opportunity for future research and this paper makes a small contribution in this regard.

Two broad approaches are used to examine patient flow through the emergency department: process improvement and formal modelling. Process improvement uses techniques such as process mapping, lean, six-sigma whereas formal modelling uses discrete event or other simulation approaches and mathematical modeling. For example, King et al. (2006) conducted a lean study for the establishment of streams for patient flows in an emergency department. Lim et al. (2002) evaluated mathematical modeling techniques used to evaluate strategies for decreasing waiting times in hospital 
emergency departments and found that the following four techniques were popular queuing analytical models, discrete event simulations, system dynamics and agent based modeling. Abo-Hamad and Arisha (2013), using a simulation model, found that reducing waiting time for those patients to be admitted into hospital led to a significant reduction in average length of stay in the emergency department. However, it was noted that while simulation is commonly discussed in the literature only a few studies indicated that results from the models were implemented into practice. For that reason, this research project does not aim to produce a simulation or other mathematically based model of the emergency department. Instead it aims to produce a conceptual model that is founded on a statistical analysis of empirical data and can be used by practitioners to better understand, and manage, the factors that influence congestion in the emergency department. As this type of influence model is rare in the literature it may also be useful to researchers in terms of providing a formal structure for future research into hospital congestion.

\section{Methodology}

The researchers had access to a data set containing details of all 47,168 presentations to the emergency department of a large suburban public hospital during calendar year 2010. The data set was analysed using descriptive statistics, statistical inference and regression analysis. 
The data set comprised nine variables (table 1). These variables were grouped under the three headings of input, process and output. Input data comprised demographic details (age and gender) and arrival details (date and time period of arrival). Process data included register-to-discharge (length of stay) and triage category. Note that triage refers to the severity of the condition of the patient and is represented by one of five colour codes in increasing order of severity: blue, green, yellow, orange and red. Output data comprised details of the discharge of the patient. Discharge type contains five categories: A\&E discharge, admitted, out-patient, external hospital and unknown. The value 'A\&E discharge' implies that the patient was discharged from the hospital back into the community. 'Admitted' implies that the patient was admitted to a bed in the hospital proper. 'Out-patient' implies that the patient was referred to one of the outpatients departments in the hospital. 'External hospital' implies that the patient was transferred to another hospital. 'Unknown' is self-explanatory. The variables were categorised as follows: week-ending, weekday, period, time category and triage were categorised as ordinal, gender and discharge type as nominal, and age and register-todischarge as ratio scale variables.

Three hypotheses are formally proposed:

H1: length of stay increases as severity of condition increases

$\mathrm{H} 2$ : length of stay increases as age increases and 
H3: length of stay is greater for patients who are admitted into the hospital proper than for those not admitted.

Correlation analysis was used to test $\mathrm{H} 1$ and $\mathrm{H} 2$. Statistical inference was used to test H1 and H3. Regression analysis was used to determine a predictive relationship between length of stay and age, severity of condition (triage) and admission. Descriptive statistical analysis was carried out using spread-sheet (Microsoft Excel 2010) statistic and pivot table functionality. The data set was imported into a statistical software analysis package (IBM SPSS Version 19) for statistical inference and regression analysis.

\section{Analysis and Discussion of Findings}

In line with the literature review section we discuss findings under the three headings of the systems paradigm: input, process and output. For use in the emergency department we translate this into patient input, treatment process and patient output.

\section{Patient Input analysis}

Descriptive statistical analysis showed that mean age of patients attending at the emergency department was 47 years and standard deviation was 21 years. Of these, 39 per cent were 25 to 50 years old and 13 per cent were over 75 years old. A visual inspection of patient age suggests that this is a bimodal distribution with two peaks: one in mid-20s and one in mid-60s. 
With respect to severity of condition, 59 per cent of patients were in the yellow triage category. The green and orange categories accounted for 16 per cent and 17 per cent respectively. Red and blue categories accounted for less than 1 per cent each. A triage category was not given in the data set for 7 per cent of patients.

With respect to gender, 52 per cent of patients were male and 48 per cent female. However, broken down by triage category it was found that males comprised a significantly higher proportion of patients presenting with both very severe and with minor conditions. Approximately 58 per cent of patients with condition red were male compared with 40 per cent female ${ }^{\mathrm{a}} ; 57$ per cent of patients with condition green were male compared with 43 per cent who were female. The majority of patients presenting with the most common triage condition, yellow, were female (52 per cent female as opposed to 48 per cent male).

The number of patients arriving was highest at the start of the week and reduced as the week went on. Monday was the busiest day of the week with 17 per cent of total patients arriving on that day. Numbers decreased between Mondays and Thursdays with a small relative increase on Fridays. There was a significant decline in arrivals over the weekend (i.e. on Saturdays and Sundays). The smallest number of arrivals at 11 per cent was on Saturdays.

\footnotetext{
${ }^{a}$ Note that these figures do not total to 100 per cent as the gender of 2.5 per cent of patients presenting with condition red was unknown.
} 
The exception to this pattern was for triage category red where there was no discernible pattern in arrivals during the week. This is intuitively as expected as patients with condition red will present immediately and will not consider waiting for a convenient time. On the other hand patients with less severe conditions present outside of weekends. A summary of patient arrivals for each weekday by triage category is given in figure 1.

Data with respect to arrivals by hour of the day and day of the week are given in table 2 . The busiest time for presentations was on Monday mornings between 8.00am and midday with almost 6 per cent of all patients presenting during that block. That block of time is also busiest across the entire week with over 28 per cent of patients presenting between 8.00am and mid-day. The second busiest block of time across the week is midday to $3.59 \mathrm{pm}$ with 26 per cent of patients presenting during that block. The least busy block of time is between 4.00am and 7.59am with only 6 per cent of patients presenting. The second least busy block of time is between midnight and 3.59 am with 7 per cent of total patients presenting during that time slot. The busiest night-time period was from midnight to $3.59 \mathrm{am}$ on Sunday mornings with 1.3 per cent of total patients presenting during that slot.

The data show that presentations were relatively constant throughout the months of the year. February had the lowest number of presentations with 7.3 per cent of the annual total while August had highest number of presentations at 8.9 per cent. Examining the 
data by triage category shows relatively constant levels of presentations for each category except for category red which shows relatively large fluctuations from 5 per cent of annual total in September to over 12 per cent of annual total in July. This analysis implies that presentations in triage category red show greater variation than those for other categories.

There is a small increase in the number of presentations in the less severe triage categories of yellow and green during the five months from May to September. This implies that patients during the five warmer months tend to present with less severe conditions. This may be because climatic conditions make travel to hospital easier during this period or it may be due to an increase in the number of minor conditions occurring during the summer months.

With respect to weeks of the year, the data showed small fluctuations in the number of presentations on a weekly basis from a high of 1,014 (first week in July) to a low of 769 (last week in December i.e. Christmas week); mean number of weekly presentations was 902 and standard deviation was $53.6^{\mathrm{b}}$. However, no discernible trend in weekly presentations was evident.

\footnotetext{
${ }^{b}$ First and last weeks of the year were excluded from these calculations as they did not contain a full seven days.
} 


\section{Treatment Process analysis}

Descriptive statistical analysis showed that the average length of stay in the emergency department was 0.49 days (11.8 hours) with a standard deviation of 0.76 days (18.2 hours). Approximately 46 per cent of patients stayed for 6 hours or less and 73 per cent of patients for 12 hours or less. On the other hand, 13 per cent of patients were in the emergency department for over 24 hours, 3 per cent for over 48 hours, and 1 per cent of patients were in the emergency department for over 72 hours. A visual inspection of the distribution of patients according to length of stay suggests that the distribution may be lognormal.

Average length of stay showed a clear positive relationship with age, increasing as age increased as shown in figure 2. For 20 to 29 year olds average duration of stay was 0.34 days (8.2 hours) while for 90 to 99 year olds average duration increased to 1.14 days (27.4 hours). This relationship between age and duration of stay is clear for triage categories yellow and orange (see figure 3) which are the most numerous categories together comprising over 75 per cent of emergency attendances. For categories red and green there is a pronounced increase in average duration of stay for patients over 70 years old.

\section{Patient Output analysis}

Descriptive statistical analysis showed that the vast majority (66 per cent) of patients who attended at the emergency department were discharged after treatment. A 
significant minority (23 per cent) were admitted into the hospital proper. A small number of patients ( 6 per cent) were forwarded on to the outpatients department. Approximately 1 per cent of patients were transferred to an external hospital. The destination of 4 per cent of patients was recorded as unknown ${ }^{c}$.

An analysis of age and discharge type showed two clear trends (see figure 4). Firstly the number of discharges decreases with age. For example, 78 per cent of presenters aged between 20 and 29 years old were discharged whereas only 49 per cent of those aged between 70 and 79 were discharged. The second clear trend is that admissions into the hospital proper increase with age. For example, less than 11 per cent of those aged between 20 and 29 were admitted whereas 40 per cent of those aged between 70 and 79 were admitted. A disproportionate number of older patients are admitted: for example, 65 per cent of admissions were for patients aged 50 or over although this age group make up only 43 per cent of total attendances. The ratio of admissions to discharges increases with age band as shown in figure 5. Patients aged 80 and over are more likely to be admitted than discharged and vice versa for patients under 80 .

An analysis of discharge type versus duration shows that length of stay in the emergency department was significantly greater for patients who were ultimately admitted (see figure 6). Average length of stay for all patients is 0.48 days (11.5 hours) whereas average length for patients admitted is 1.02 days (24.5 hours); this is

\footnotetext{
${ }^{\mathrm{c}}$ The triage category of the vast majority of these was also unknown.
} 
significantly greater than an average length of stay of 0.3 days ( 7.2 hours) for patients who are discharged. It is also clear from figure 7 that length of stay for patients admitted increases significantly with age. Longer length of stay may be due to the nature of the treatment carried out on patients due for admission, the nature of treatment that older patients typically require, or waiting for a bed to become available in the main hospital.

A cross-tabulation analysis of discharge type versus triage category shows that the vast majority of patients with minor conditions were discharged: 95 per cent of patients with green and blue conditions were discharged as were 70 per cent of those with condition yellow. Patients presenting with more severe conditions were more likely to be admitted: 57 per cent of patients with condition orange and 47 per cent of those with condition red were admitted. Of the 10,997 patients admitted to the main hospital through the emergency department the vast majority were of condition orange or yellow: 41 per cent and 56 per cent respectively.

With respect to day of the week, there is a small rise in the proportion of patients discharged at weekends: on average 65 per cent of patients who present during the week are discharged whereas this increases to 70 per cent at weekends. 
Correlation analysis $^{\mathrm{d}}$ showed a positive relationship between severity of condition (triage) and length of stay $(\mathrm{r}=0.283, \mathrm{p}<0.01)$. Analysis of variance showed that average length of stay varied according to severity of condition (triage) $(\mathrm{F}=3808 ; \mathrm{p}<$ 0.001). Both of these tests provide support for hypothesis H1: that length of stay increases with severity of condition. Correlation analysis showed a positive relationship between age and length of stay $(r=0.213, \mathrm{p}<0.01)$, supporting hypothesis $\mathrm{H} 2$ : that length of stay increases with age. T tests showed that average length of stay is greater for patients admitted ${ }^{\mathrm{e}}$ into the hospital proper than for patients not admitted $(\mathrm{t}=93.43 ; \mathrm{p}$ $<0.001$ ), supporting hypothesis H3: that length of stay increases with admission to the hospital proper. Patients admitted into the hospital proper on average spent 0.7 days (17 hours) longer in the emergency department than did patients who were not admitted.

Regression analysis with log of length of stay as the dependent variable and age, severity of condition (triage) and discharge type as independent variables showed a relationship that was strong in explanatory power $\left(\mathrm{R}^{2}=0.352\right)$ and statistically significant $(\mathrm{F}=7971 ; \mathrm{p}<0.001)$ and yielded the following regression equation:

$\ln ($ length of stay $)=-3.268+0.005 *$ age $+0.495 *$ triage $+0.995 *$ discharge type

\footnotetext{
${ }^{\mathrm{d}}$ To carry out these correlation and regression analyses the triage variable was re-coded according to severity of condition: blue $=1$, green $=2$, yellow $=3$, orange $=4$ and red $=5$. Note that this assumes that the severity of the condition increases in a linear fashion which may not necessarily be true. These results should therefore be interpreted with some caution.

e To carry out the regression analysis and t-tests the discharge-type variable was re-coded as follows: Admitted $=1$; all other discharge types $=0$.
} 
where length of stay is given in days, age is in years, severity of condition (triage) is on a scale of one to five, and discharge type is 1 for admitted and 0 for all other discharge types. For example, this equation predicts that a 50 year old with severity condition (triage) orange who is to be admitted into the hospital proper will spend on average 23 hours in the emergency department; a 50 year old with severity condition orange who does not require admission will have predicted average length of stay of 8.5 hours.

Given the nature of the data, the validity of the regression model used was tested to ensure that the assumptions of the general linear model were not violated. In particular the level of multicollinearity amongst variables and autocorrelation between patient values was tested. To test multicollinearity, the Variance Inflationary Factor (VIF) was calculated for each independent variable. The values estimated (maximum of 1.22) were all comfortably below accepted levels for VIF of 10 (Hair et al., 1995; Kennedy, 1992; Neter et al., 1989). The level of autocorrelation was measured using the Durbin-Watson statistic. Its value of 1.82 is within the accepted range for this value, close to the optimal value of 2 (Durbin and Watson, 1950). Finally, residual plots did not demonstrate any assumption violations.

\section{A model of emergency department congestion}

This paper examined one full year of data on the patient supply chain through the emergency department of a major semi-urban hospital. Several clear trends were evident from the data. The busiest day of the week was found to be Monday and the busiest 
period of the week was found to be Monday morning. Mornings were generally busier than afternoons. Women predominate in the most common triage category, yellow, whereas men predominate in all other triage categories i.e. more men than women present with more serious conditions and with less serious conditions. The number of admissions increased in age and the ratio of admissions to discharges also increased in age. Patient length of stay in the emergency department was found to increase with age, severity of triage category, and admission into the hospital proper. A regression equation of length of stay versus age, triage and admission was proposed. This equation could be used to forecast patient length of stay but its usefulness needs to be verified in practice.

The findings support the view of the literature that more patients present to the emergency department during normal working hours than during the evenings or during weekends. The findings also support the literature view that length of stay in the emergency department increases with age. It is also a finding that length of stay is greater for patients who are ultimately admitted into the hospital. There are a number of possible reasons for this including frailty of patient, type of illness, criticality of condition, and bed availability in the main hospital. Further detailed examination of this handover situation between the emergency department and the main hospital is a topic for future research. 
Congestion is a function of the number of patients present in the emergency department at any one time. Overcrowding occurs when the number of patients in process exceeds the capacity of the unit. Congestion in turn is a function of the average number of arrivals and the length of stay of patients in the emergency department. In the field of operations research the relationship between arrivals, cycle time, and number in the system is known as Little's law (Little, 2011). The data showed that the number of arrivals is influenced by temporal considerations such as the day of the week, time of the day and to a lesser extent month of the year. The data have shown that length of stay is influenced by patient related factors such as age, severity of condition and need for admission.

O'Cathain et al. (2013) found that the higher the number of available acute hospital beds the higher the admissions from the emergency department into the main hospital. Manzano-Santaella (2011) suggests that elderly patients are often associated with delayed discharge making them less desirable to a main hospital where length of stay is a performance indicator. Dusheiko et al. (2011) found that better management of care in the community was associated with lower emergency admission rates. With respect to resources, queuing theory tells us that increasing the number of clinicians ${ }^{\mathrm{f}}$ available in the emergency department will increase the rate at which patients will be seen, leading to a reduction in patient length of stay (Harris, 2010). In addition, it is likely that the

\footnotetext{
${ }^{\mathrm{f}}$ This may require careful balancing of the resources carrying out the different clinical services provided in the emergency department.
} 
level of congestion in the emergency department will be influenced by institutionspecific factors such as efficiency of work practices, effectiveness of business processes, capability of management, design and layout of the physical space, and use of information technology (Van der Vaart, 2011).

Putting these elements together a model of emergency department congestion has been developed (figure 7). The model is drawn in the style of an influence diagram ${ }^{\mathrm{g}}$ from the system dynamics literature (Senge, 1990). The direction of influence of one variable on another is indicated by an arrow with a plus or minus sign at its head. A plus (minus) sign indicates that an increase (decrease) in one variable leads to an increase (decrease) in the downstream variable. This research project has shown that an increase in patient related factors such as age and severity of condition leads to an increase in length of stay. It has also been shown that time-related factors influence patient arrivals, an influence that may be positive or negative. Little's Law suggests that an increase in length of stay, or in patient arrivals, leads to an increase in congestion. The literature suggests that an increase in emergency department resources such as doctors and nurses or process innovations such as use of 'fast tracks' may influence emergency department congestion. Availability of beds in the main hospital also appears to influence length of stay in the emergency department. These may have a positive or negative influence depending on the nature of such factors. Emergency department specific factors and

\footnotetext{
g also known as a causal loop diagram
} 
hospital specific factors are included in the model in softer font as these entities and relationships were not tested in this research project. Availability of community resources such as general practitioners, home help or nursing homes is also likely to impact on the number of patient arrivals in emergency departments. Such community specific factors may also have an influence on emergency department congestion.

It is also reasonable to assume that congestion in turn leads to a reduction in efficiency within the emergency department and a consequent increase in length of stay. This creates a reinforcing feedback loop as shown in figure 7 . While patient, time and bed related factors have been validated through this research project, further research work is necessary in order to confirm and validate the complete model. In particular the influence of available emergency department, hospital and community resources on emergency department congestion requires empirical validation.

In summary, the paper makes a number of contributions to research and practice. Firstly it provides an in-depth study of attendance activity in an emergency department over a full calendar year. This is a contribution in its own right as the literature provides few complete statistical descriptions of emergency department attendances. Secondly, it provides further empirical evidence to support extant literature with respect to emergency department attendances in terms of seasonality, time of day, day of week, severity of condition, and age and gender of patients. Thirdly, it provides results for a major hospital in Ireland, a country that is relatively under-examined with respect to 
emergency department research. Fourthly, it puts forward a formal regression equation that may be used to predict length of stay in the emergency department. Given that patient length of stay is such a critical variable in emergency department congestion, this may be a useful practical tool for practitioners and hospital managers. Finally, it puts forward a tentative formal influence model of emergency department congestion that may be useful to both practitioners and researchers.

\section{Conclusion}

Attendances at the emergency department of an Irish hospital over a full calendar year were analysed statistically. Patterns of attendances were found to largely match those of other countries confirming extant research and also providing useful insight into emergency department activity in Ireland, a hitherto largely under-researched context. Examination of these patterns yielded three main influencers of congestion in emergency departments: patient-related factors, time-related factors and hospital-related factors. These factors were incorporated into a formal model of emergency department congestion. This model provides a practical tool to practitioners and hospital managers and also provides a useful framework for further research into the topical area of emergency department congestion.

There are a number of limitations to this research project. Data was limited to one calendar year and for one hospital only and the analysis was limited to statistical analysis of this data set. The data set itself was limited to seven independent items, a 
relatively small number. Future research could examine multiple years of admissions data and include additional items such as time to first medical and mode of attendance (e.g. ambulance, walk-in, or GP referral). More sophisticated statistical tools such as general linear analysis or structural equation modelling could be brought to bear on the data to further explore the linkages between age, triage, discharge mode and length of stay. Alternatively system dynamics, agent-based or discrete-event simulation modelling tools could be used to analyse further the emergency department as a complex, dynamic system. The proposed conceptual model may provide a framework for further research on emergency department congestion. In particular, discrete event or other simulation modelling could be used to examine the behaviour of the feedback loop as shown in figure 7.

The research did not take into account weather conditions, mode of entry (e.g. ambulance, walk-in), or type of ailment. Nor did the project examine any managerial interventions or community interventions that may have taken place prior to or during the year being examined. Extending this research project to take into account emergency department resources, hospital bed availability, and community care initiatives could provide useful avenues for future research. Extending the examination of admission data from one to several years and determining the impact of managerial interventions during this time could also provide a future direction for the research project. 


\section{Acknowledgement}

The authors would like to thank the staff of the hospital for their support. This research received no specific grant from any funding agency in the public, commercial, or notfor-profit sectors.

\section{References}

Abo-Hamad, W. and A. Arisha. Simulation-based framework to improve patient experience in an emergency department. European Journal of Operational Research 2013; 224:154-166.

Biber, R, HJ Bail, C Sieber, P Weis, M Christ and K Singler. Correlation between age, emergency department length of stay and hospital admission rate in emergency department patients aged $\geq 70$ years. Gerontology, 2013; 59(1):1722.

Cerrito, PB and D Pecoraro. Visits to the emergency department as transactional data. Journal of Healthcare Management 2005; 50(6): 389-395

Cochran, J. K., and Roche, K. T. A multi-class queuing network analysis methodology for improving hospital emergency department performance. Computers \& Operations Research 2009; 36(5), 1497-1512.

Dobrzykowski, D, VS Deilami, P Hong and S-C Kim. 2013. A structured analysis of operations and supply chain management research in healthcare (1982-2011). International Journal of Production Economics 2013; 147: 514530

Durbin, J and GS Watson. Testing for Serial Correlation in Least Squares Regression, I. Biometrika. 1950; 37(3-4):409-428.

Dusheiko, M., T. Doran, H. Gravelle, C. Fullwood and M. Roland. Does higher quality of diabetes management in family practice reduce unplanned hospital admissions? Health Services Research 2011; 46(1):27-46. 
Guttman, A., Schull, M.J., Vermeulen, M.J., and Stukel, T.A.. Association between waiting times and short term mortality and hospital admission after departure from emergency department: population based cohort study from Ontario, Canada. BMJ 2011;342:d2983 doi:10.1136/bmj.d2983.

Hair, J.F.Jr., Anderson, R.E., Tatham, R.L. and Black, W.C. 1995. Multivariate Data Analysis (3rd ed). New York: Macmillan

Harris, M. Little's Law: the science behind proper staffing. Emergency Physicians Monthly 2010; (Feb).

Kennedy, P. 1992. A Guide to Econometrics. Oxford: Blackwell

Khare, RK, ES Powell, G Reinhardt and M Lucenti. Adding More Beds to the Emergency Department or Reducing Admitted Patient Boarding Times: Which Has a More Significant Influence on Emergency Department Congestion? Annals of Emergency Medicine 2009; 53(5):575-585.

King, D.L., Ben-Tovim, D.I. and Barsham, J. Redesigning emergency department patient flows: application of lean thinking to healthcare. Emergency Medicine 2006; 18:391-397.

Lim, M. E., Nye, T., Bowen, J. M., Hurley, J., Goeree, R., and Tarride, J. E. Mathematical modeling: the case of emergency department waiting times. International Journal of Technology Assessment in Health Care 2002; 28(02): 93-109

Lin, B Y-J, TTH Wan, C-P Cliff Hsu, F-R Hung, C-W Juan and C-C Lin. Relationships of hospital-based emergency department culture to work satisfaction and intent to leave of emergency physicians and nurses, Health Services Management Research 2012; 25(2): 68-77.

Little, J. Little's Law as viewed on its $50^{\text {th }}$ anniversary. Operations Research 2011; 59(3):536-549. 
Manzano-Santaella, A. From bed-blocking to delayed discharges: precursors and interpretations of a contested concept. Health Services Management Research 2010; 23:121-127.

Maull, R. S., Smart, P. A., Harris, A., and Karasneh, A. A. F. An evaluation of 'fast track' in A\&E: a discrete event simulation approach. The Service Industries Journal 2009; 29(7): 923-941.

Neter, J., Wasserman, W. and Kutner, M. H. 1989. Applied Linear Regression Models. Homewood, IL: Irwin

O'Cathain, A., E. Knowles, R. Maheswaran, J. Turner, E. Hirst, S. Goodacre, T. Pearson and J. Nicholl. Hospital characteristics affecting potentially avoidable emergency admissions: National ecological study. Health Services Management Research 2013; 26(4):110-118.

Richardson, D. No relationship between emergency department activity and triage categorization, Academic Emergency Medicine 1998; 5(2):141-145

Rondeau, KV and LH Francescutti. Emergency department overcrowding: the impact of resource scarcity on physician job satisfaction. Journal of Healthcare Management 2005; 50(5): 327-340.

Senge, P. The Fifth Discipline. Century Press, 1990.

Van der Vaart, T., Vastag, G. and Wijngaard, J. Facets of operational performance in an emergency room (ER), International Journal of Production Economics 2011; 133(1):201-211.

Wargon M., Casalino E. and Guidet B. From model to forecasting: a multicentre study in emergency departments. Academic Emergency Medicine 2010;17(9): 970-978. 
Xu M., Wong, TC, and Chin KS. Modeling daily patient arrivals at emergency department and quantifying the relative importance of contributing variables using artificial neural network. Decision Support Systems 2013; 54:1488-1498 
Table 1. Data set variables and permitted values

\begin{tabular}{|l|l|l|}
\hline Title & Description & Values/ Format \\
\hline Weekday & Arrival day of the week & $\begin{array}{l}\text { Monday, Tuesday, Wednesday, Thursday, } \\
\text { Friday, Saturday, Sunday }\end{array}$ \\
\hline Weekending & Arrival week of the year & yyyy/mm/dd e.g. 2010/01/17 \\
\hline Period & Arrival month of the year & yyyy-mm e.g. 2010-01 \\
\hline Time category & Arrival time (block of 4 hours) & hh:mm to hh:mm e.g. 00:00 to 03:59 \\
\hline Triage & Criticality of presenting condition & Red, orange, yellow, green, blue \\
\hline Register to discharge & Length of stay of patient & hh:mm:ss e.g. 06:12:30 \\
\hline Type of discharge & $\begin{array}{l}\text { Destination of patient after } \\
\text { treatment }\end{array}$ & $\begin{array}{l}\text { A\&E discharge, admitted, out-patient, } \\
\text { external hospital, unknown }\end{array}$ \\
\hline Age & Age of patient (years) & nnn e.g. 26 \\
\hline Sex & Gender of patient & M, F, unknown \\
\hline
\end{tabular}

Table 2. Patient arrivals (per cent)

\begin{tabular}{|c|c|c|c|c|c|c|c|c|c|}
\hline & & \multicolumn{8}{|l|}{ Weekday } \\
\hline $\begin{array}{l}\text { Time } \\
\text { Category }\end{array}$ & & Monday & Tuesday & Wednesday & Thursday & Friday & Saturday & Sunday & $\begin{array}{l}\text { Grand } \\
\text { Total }\end{array}$ \\
\hline $\begin{array}{l}00: 00 \\
03: 59\end{array}$ & to & 1.05 & 0.84 & 0.96 & 0.91 & 1.04 & 1.13 & 1.29 & 7.22 \\
\hline $\begin{array}{l}04: 00 \\
07: 59\end{array}$ & to & 0.94 & 0.86 & 0.98 & 0.78 & 0.90 & 0.81 & 0.90 & 6.17 \\
\hline $\begin{array}{l}08: 00 \\
11: 59\end{array}$ & to & 5.58 & 4.86 & 4.12 & 4.01 & 4.81 & 2.47 & 2.16 & 28.01 \\
\hline $\begin{array}{l}12: 00 \\
15: 59\end{array}$ & to & 4.51 & 3.80 & 3.66 & 3.56 & 3.92 & 3.15 & 3.37 & 25.98 \\
\hline $\begin{array}{l}16: 00 \\
19: 59\end{array}$ & to & 3.28 & 3.00 & 2.76 & 2.87 & 3.11 & 2.05 & 2.35 & 19.42 \\
\hline $\begin{array}{l}20: 00 \\
23: 59 \\
\end{array}$ & to & 2.01 & 1.85 & 1.90 & 1.95 & 1.91 & 1.75 & 1.83 & 13.20 \\
\hline Grand Tota & & 17.37 & 15.22 & 14.38 & 14.08 & 15.69 & 11.35 & 11.90 & 100.00 \\
\hline
\end{tabular}




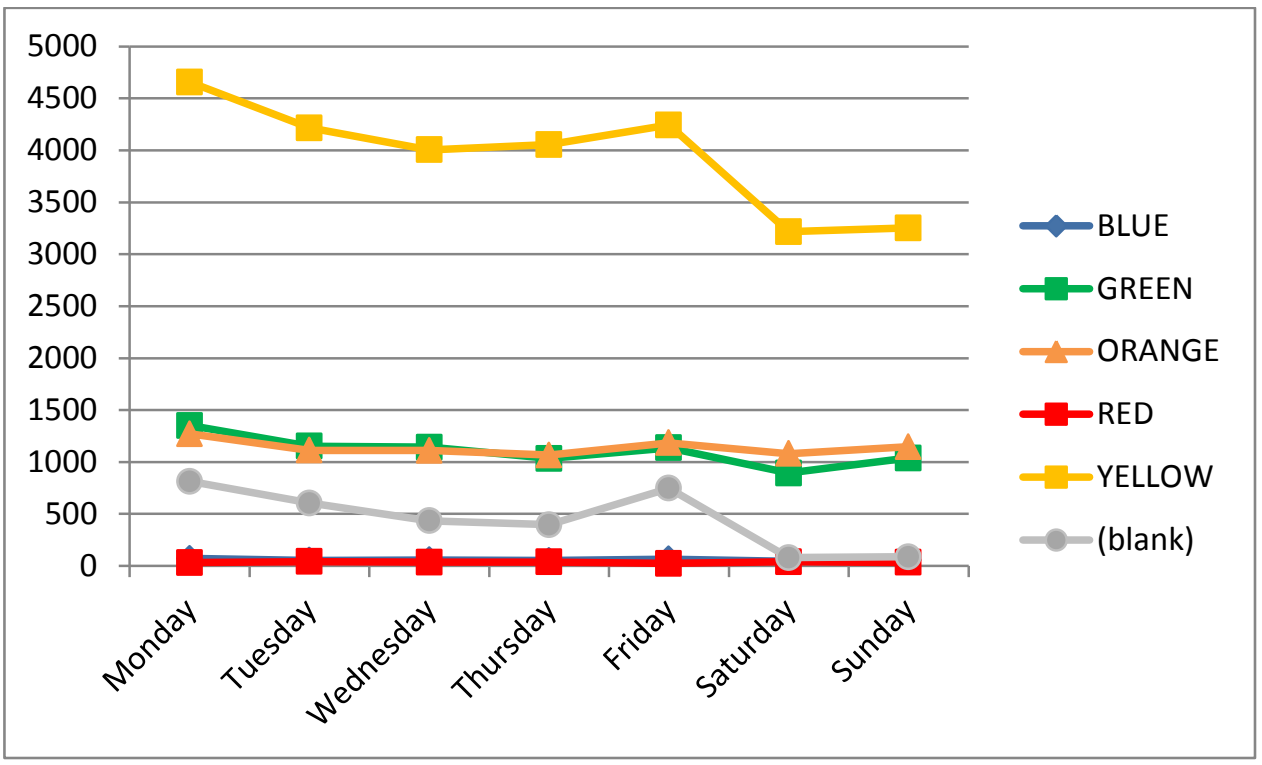

Figure 1. Patient arrivals by weekday (by triage category) 


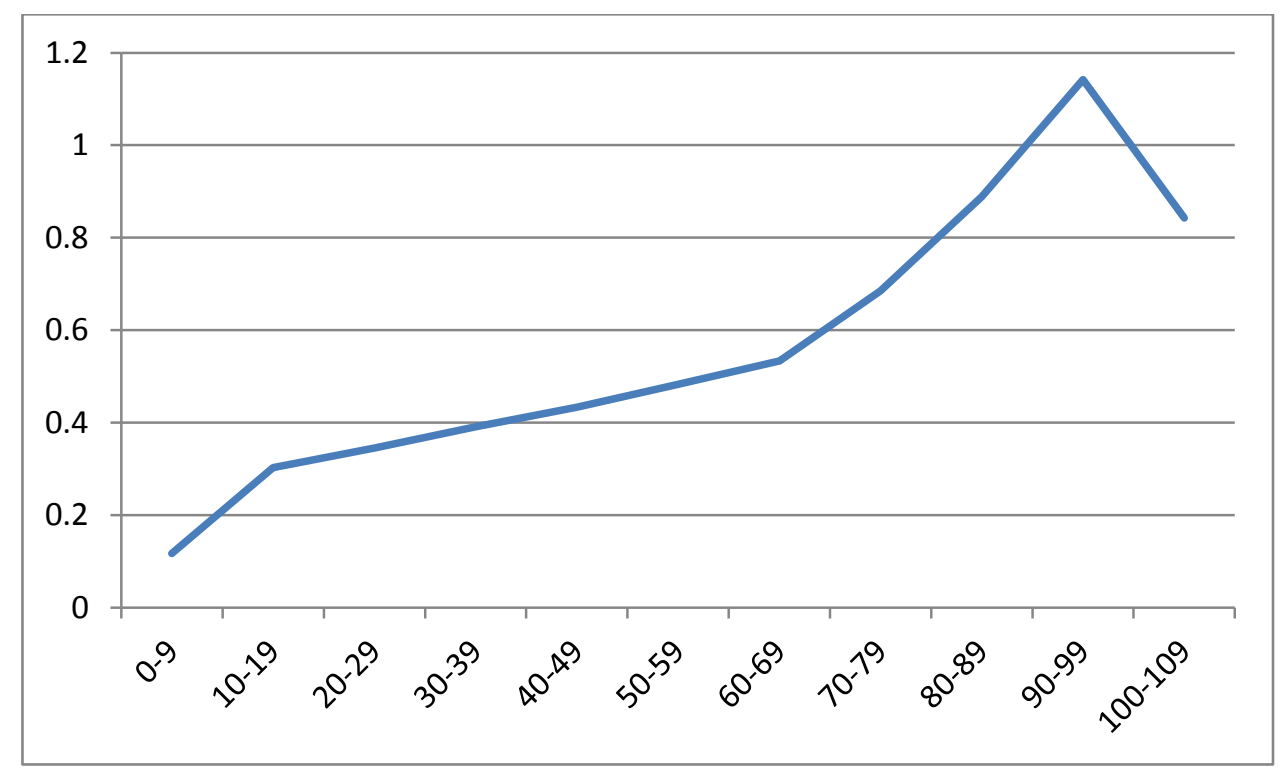

Figure 2. Length of stay in days by age

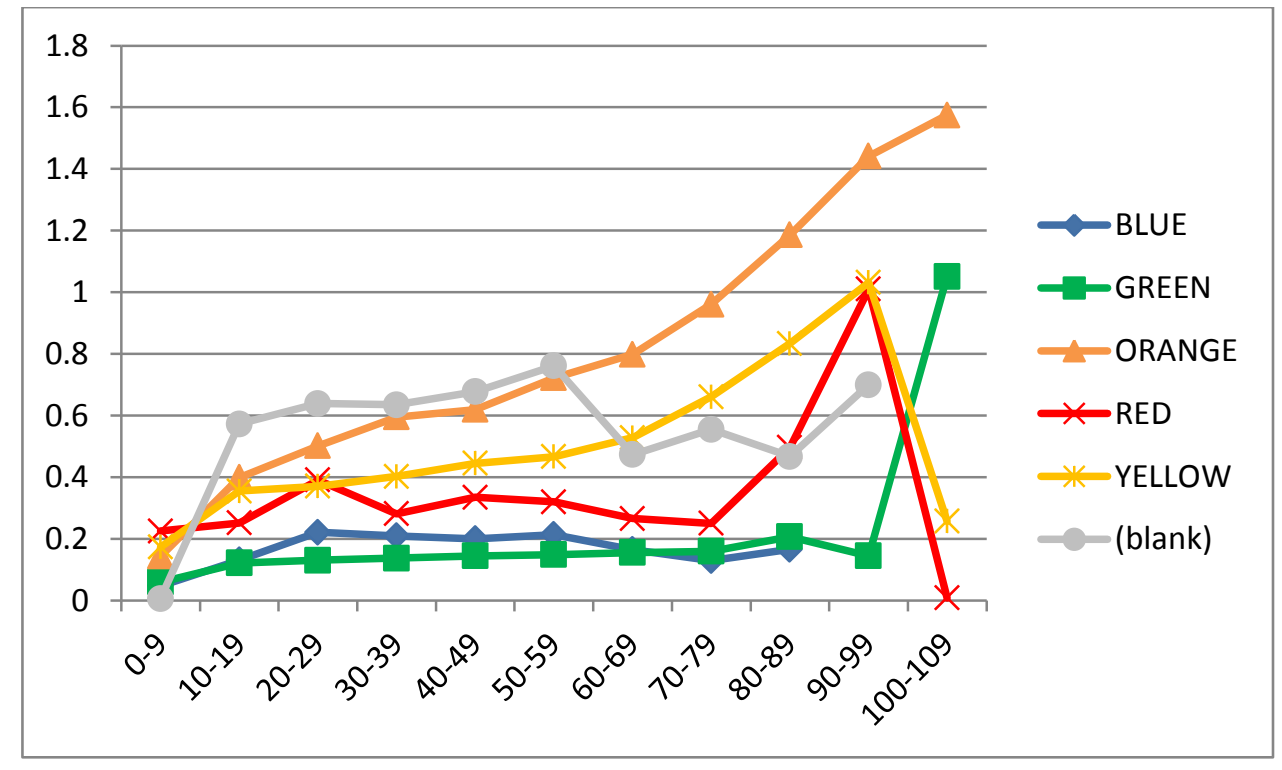

Figure 3. Length of stay in days by age (by triage category) 


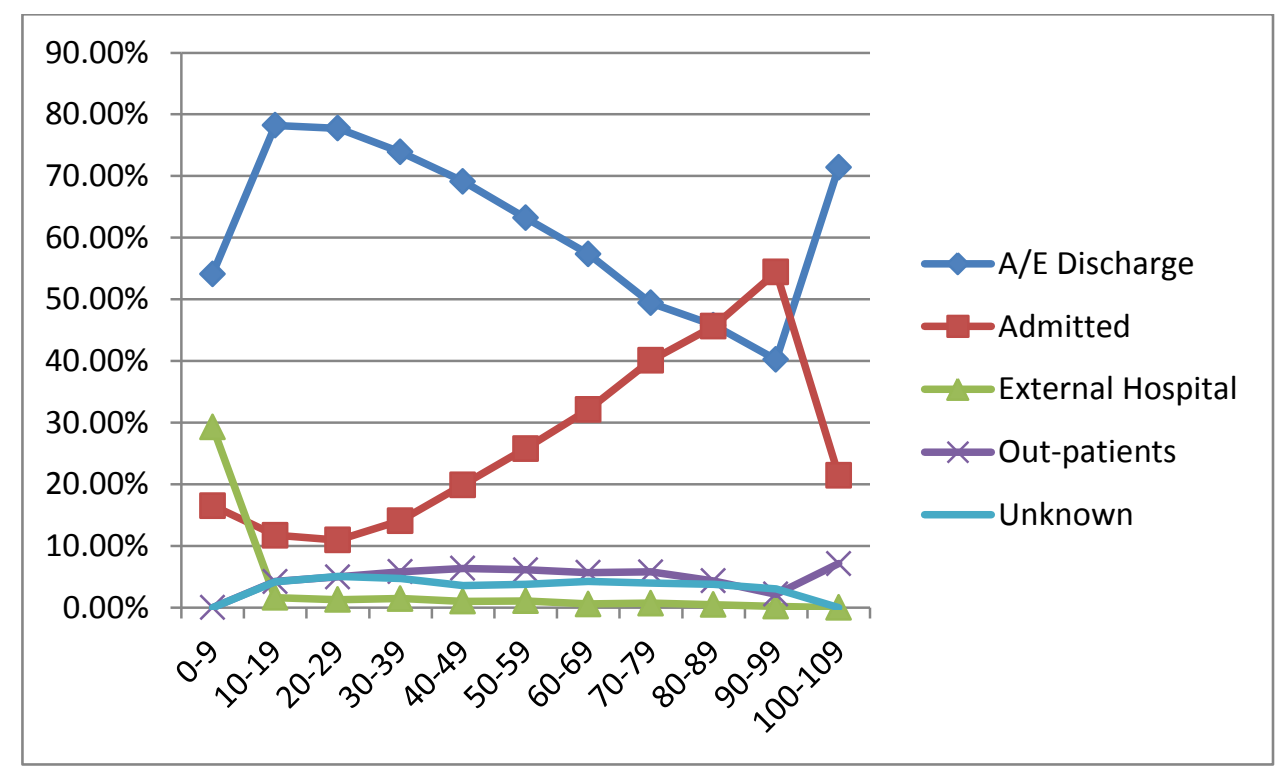

Figure 4: Patient discharge by age (by discharge type)

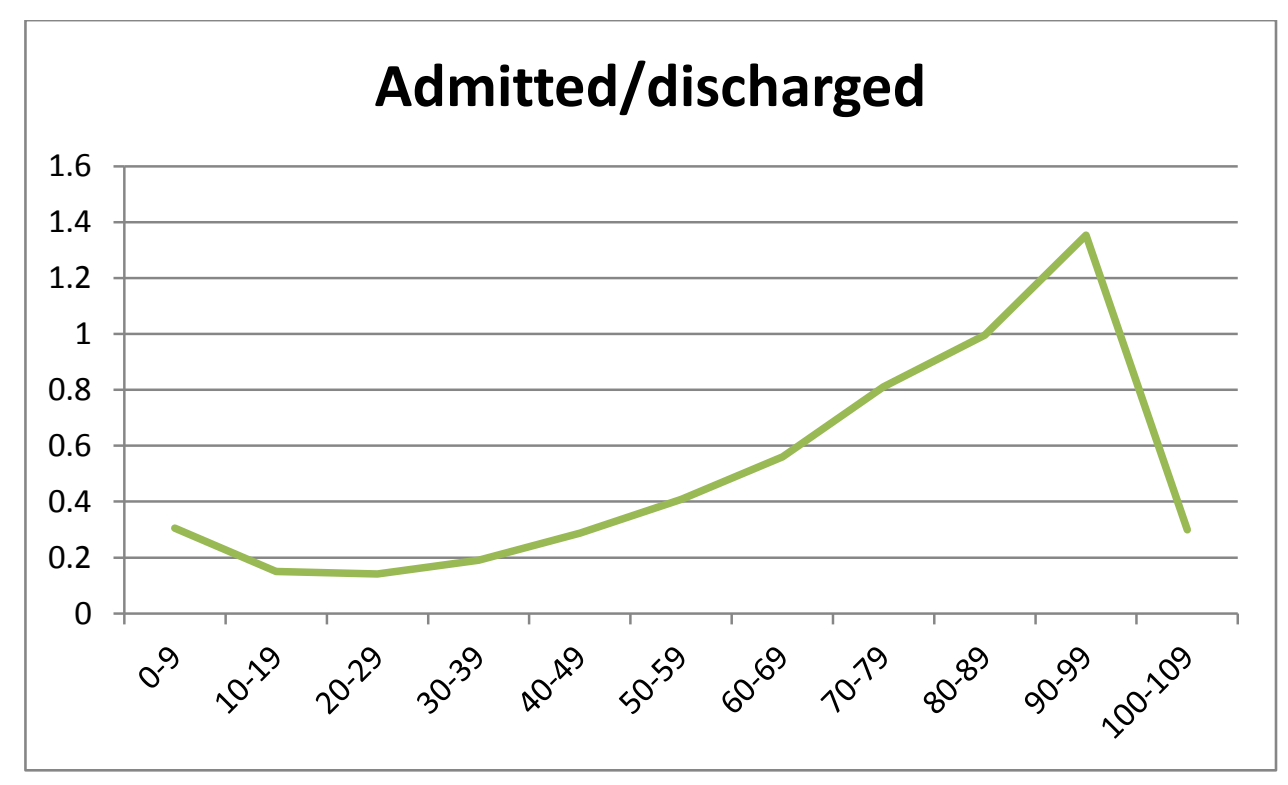

Figure 5. Ratio of patients admitted to patients discharged by age 


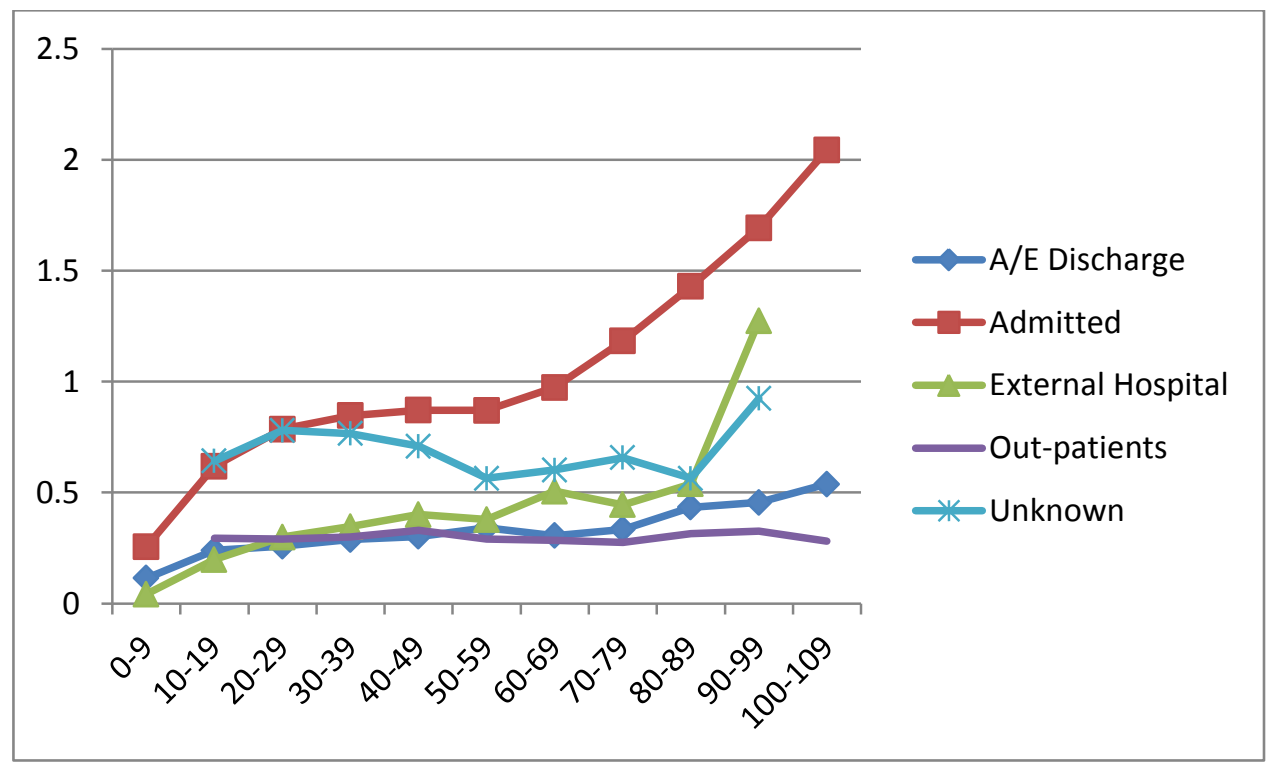

Figure 6. Length of stay in days by age (by discharge type) 
e.g. time of day, day of week,

e.g. resource availability physical layout,

process design,

information technology, month of year

managerial skill

ED specific factors

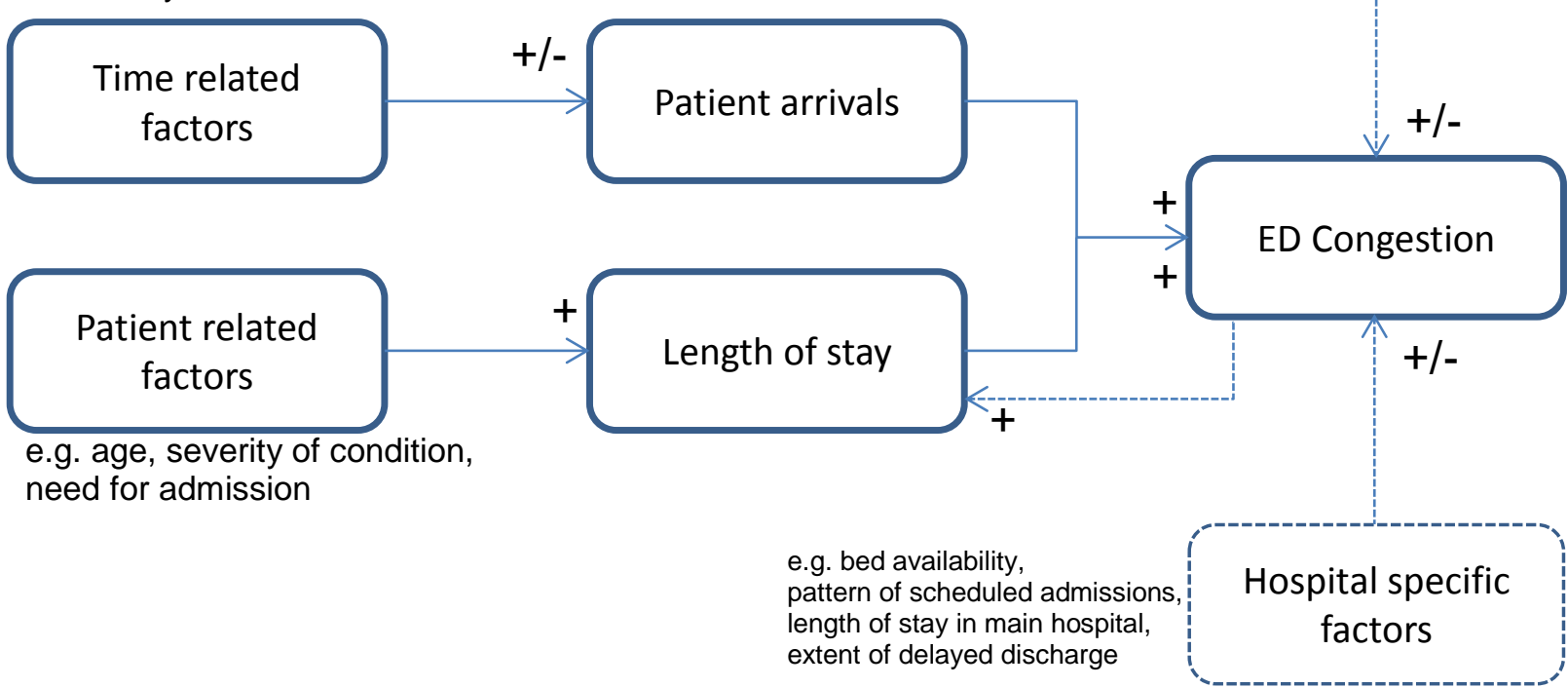

Figure 7. Influence model of emergency department congestion 